TRANSPORT IN POROUS MEDIA

publishes book reviews and information on relevant conferences. It also encourages the submission of reviews on topics of interest to its readers, with the objective of presenting a critical survey of the work done so far and suggesting directions for further research.

Altogether, the journal can be counted a success. It provides an excellent forum for the interchange of ideas between those scientists and engineers who, although working in different disciplines, have a common interest in the phenomena associated with transport in porous media.

C.A. Brebbia is Director of the Computational Mechanics Institute, Wessex Institute of Technology, Ashurst Lodge, Ashurst, Southampton SO42AA, UK

\section{Use and abuse of the Earth}

Brian Bell

Applied Geochemistry. Editor Brian Hitchin. Pergamon. 6/yr. UK and North America £65, \$105, elsewhere $£ 86.44$, $\$ 137.84$.

Applied Geochemistry was launched in 1986 as the official journal of the International Association of Geochemistry and Cosmochemistry. As its title suggests, it sets out to publish articles which illustrate how geochemical principles can be employed to solve problems related to exploration for Earth resources (fuels and minerals), pollution of the environment, agriculture, medicine and other related fields. The issues published to date contain contributions on an excellent spread of topics, and it is to be hoped that this will continue in the future.

Geochimica et Cosmochimica Acta, sister journal of Applied Geochemistry, is complementary in scope, dealing with more theoretical aspects of geochemistry and petrology. Authors should carefully assess the partition coefficient of their contribution with respect to the journal chosen, and ensure that their article is wholly compatible!

Applied geochemistry has developed considerably over the past few years and it is surprising that more journals have not surfaced in order to meet the demand for publication space. Journal of Geochemical Exploration dates back to 1972 , and is a well-respected publication which deals successfully with exploration techniques involving geochemical studies for fuel and mineral resources. However, the remit of
Applied Geochemistry appears to be much broader, and it is this feature which should allow it to develop its own style and coverage. In particular, environment- and health-related geochemical investigations are taking a much more prominent place in the public eye, and should prove fertile fields over the next few years.

The journal consists of articles, both short and long, and the processing time appears to be as little as three months in some instances. Production quality is

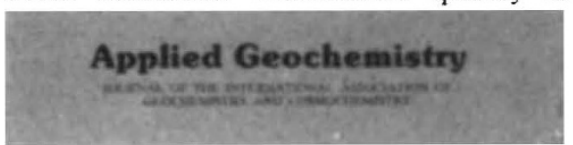

uniformly high. Reviews, per se, do not appear to be part of the present remit; that is a pity, because I feel that the incorporation of this type of feature would open up the subject of applied geochemistry to a much wider readership.

A common criticism of journals, both new and old, is that of cost. Fortunately, through membership of the International Association of Geochemistry and Cosmochemistry ( $\$ 10$ in 1987), individuals can obtain the journal for an additional \$15 per year. Otherwise, the journal is, in common with most scientific publications, expensive.

It is usual to hear complaints about the appearance of yet another journal. But I suspect that many Earth scientists, and in particular geochemists, will find in Applied Geochemistry a journal which deals with what interests them, and which will save them from having to thumb through a number of other publications.

Brian Bell is a Lecturer in the Department of Applied Geology, University of Strathclyde, Glasgow GI IXJ, UK.

\section{Promise of riches from the east}

\section{Robert Shackleton}

Journal of Southeast Asian Earth Sciences. Editor-in-chief B.K. Tan. Pergamon. 4/yr. $U K$ and North America £45, \$75; elsewhere $£ 61.02, \$ 97.30$.

THus new journal promises well. The region covered is of outstanding interest to Earth scientists, with its complex system of rapidly moving and rotating plates and microplates, and its immense mineral and hydrocarbon wealth. Literature on it has until now been scattered on a subject basis or buried in local publications in a variety of languages. The unifying view provided by plate tectonic theory implies that now, more than ever, it is important to see as a whole the evidence from many diverse branches of the Earth sciences. Regional as well as subject- based journals are therefore essential.

Judging by the first four issues of Vol. 1 (1986), Journal of Southeast Asian Earth Sciences is well on the way to fulfilling that need. The balance and variety of topics is excellent: tectonics, oil and mineral resources, palaeomagnetism, seismic exploration techniques, petrogenesis, stratigraphy and palaeontology and more are covered in the first volume. The papers, usually about ten pages long, are well-written, well-illustrated and most are convincing. An exception is the long article, published as a special issue (Vol. 1, No. 3), on "The Palaeoposition of India". It is confused, inaccurate and outof-date, and will do the reputation of the journal no good at all.

One purpose of a regional journal should be to enable those working in the

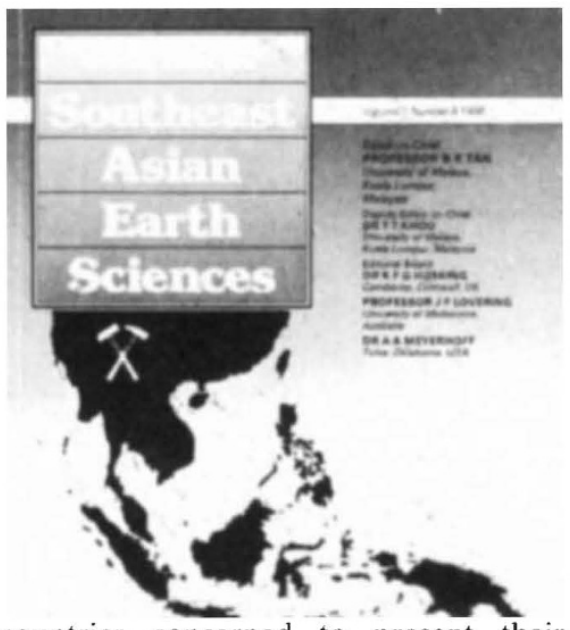

countries concerned to present their results to the world scientific community. Much of the basic data of geology comes from fieldwork and in the long run this will only be carried out by those who live there. The new journal has not yet tapped the resources of the indigenous scientists: one hopes that politics have not proved an obstacle. So far, most of the papers have come from scientists outside Asia. Without sinking into parochialism, a balance is needed between internal closeup views and external, often broad-brush interpretations illustrated with platetectonics cartoons.

Production, format and illustrations (even some, usefully in colour) are excellent. Dates of submission of papers are not given, but publication appears to be quick. Refereeing, however, needs attention.

The generally high quality of the papers and the exceptional interest of the region make this a journal that should be taken by all Earth science libraries, by organizations concerned with oil and mineral resources, and by many individual Earth scientists. A final attraction is that the price is reasonable.

Robert Shackleton is a Senior Research Fellow in the Department of Earth Sciences, Open University, Milton Keynes MK76AA, UK. 